\title{
Lead Levels among Various Deciduous Tooth Types
}

Michael B. Rabinowitz, ${ }^{1,2}$ David Bellinger, ${ }^{1}$ Alan Leviton, ${ }^{1}$ and Jung-Der Wang ${ }^{2}$

${ }^{1}$ Neuroepidemiology Unit, Children's Hospital, Boston, Massachusetts 02115, USA and ${ }^{2}$ Graduate Institute of Public Health, National Taiwan University,

Taipei, Taiwan

The amount of lead in deciduous teeth has been used extensively as a marker for infant lead exposure and body burden (Needleman et al 1972 and Fergusson et al 1989). However, the pattern of lead abundances among the various tooth positions in a child's mouth appears to be non-uniform. Several investigators have reported that, on average, shed incisors have higher lead concentrations than molars (Mackie et al 1977 and Pinchin et al 1978). Shapiro et al (1975) reported that canines have more lead than incisors, while Patterson et al (1988) found that incisors have more than canines. Teeth from the lower jaw have been reported to have more lead than upper teeth (Pinchin et al 1978), and the opposite relationship has also been demonstrated (Smith et al 1983).

Taken together these findings show an apparentiy inconsistent pattern among the tooth types. These comparison are complicated by different research groups using different portions of the tooth (ie, some use the whole crown, some use seconday dentin, and others the circumpulpal dentin), so some of the variation among tooth types might be an artifact of analytical techniques. Anatomical variability among tooth types or population based differences in exposure patterns might also account for some of these apparent discrepancies.

This issue is of significance to those who wish to compare the lead burden of children but have available teeth from different positions from the various children. By examining a large number of teeth from two different populations, we hope to explore the more universal aspects of any variability among tooth types.

Send reprint requests to M. B. Rabinowitz, Marine Biological Laboratory, Woods Hole, MA 02543 USA. 
As part of on-going studies of the role of lead in child development, we collected shed teeth from a cohort of unexceptional children who have been followed from birth in Boston. Details of the population (Needleman et al 1984) and chemical analysis (Rabinowitz et al 1989) have been published. The other cohort was primary school children in Taiwan, the Republic of China (Rabinowitz et al 1991). Two of those seven schools were chosen because they were near lead smelters, and five schools in urban Taipei. The teachers in grades 1 to 3 asked the children for any shed teeth over a 14 week period. The mean (SD) ages of shedding was $7.2(.7)$ years for incisors, $8.2(.8)$ for canines and $8.3(.9)$ for molars. There was no difference in these ages between the children near the smelters or in the city for any tooth type $(t=.7$, $p=.5)$. All of these teeth were treated exactly the same to isolate the post-natal dentin and measure lead by anodic stripping voltametry.

The lead was determined in two portions of dentin taken from the zone presumably representative of postnatal deposition. After washing, cross-sectional slabs of the shed tooth material were obtained by sagittally slicing the tooth with a low-speed saw. This slab was wrapped with Parafilm, and a hand chisel was used to isolate the desired portions. A cut was made from just below the cementum-enamel junction, which was visible in the silhouette of the tooth, to a point midway between the top of the pulp cavity and the crown. For incisors this cut approximates the neonatal line. A midline cut was also made. For deciduous teeth with the normal amount of root resorption, this yielded two enamel free specimens of $10-15 \mathrm{mg}$ each from the interior.

Identical standards and instruments were used for both populations. Statistical comparisons use a 2-tailed Student's t-test of the logarithm of the lead concentration.

\section{RESULTS AND DISCUSSION}

In general teeth from American and Chinese children have overlapping ranges of lead concentrations (Table 1). In both cohorts, maxillary and mandibular teeth have the same average lead concentrations, whether all teeth or only incisors are considered. Concerning lateral and central incisors, in Boston the upper central incisors had more lead $(p=.004)$, but in Taiwan this difference was absent. In both cohorts the incisors have more lead than canines. However, the 
Table 1. Dentin lead levels in deciduous teeth from two cohorts

\begin{tabular}{|c|c|c|c|c|c|c|c|c|}
\hline \multirow{2}{*}{\multicolumn{2}{|c|}{ Tooth Type }} & \multicolumn{3}{|c|}{ Taiwan } & \multicolumn{4}{|c|}{ Boston } \\
\hline & & $\mathbf{N}$ & Mean & SD & $\mathbf{N}$ & & Mean & SD \\
\hline \multicolumn{9}{|l|}{ Incisors } \\
\hline AII & & 567 & 4.5 & 3.4 & 2187 & 3.4 & 2.6 & *，\# \\
\hline Centra & & 284 & 4.4 & 2.8 & 1336 & 3.4 & 2.4 & (2) \\
\hline $\mathrm{upp}$ & per & 161 & 4.4 & 2.9 & 617 & 3.5 & 2.6 & \\
\hline Low & wer & 123 & 4.4 & 2.8 & 719 & 3.4 & 2.3 & \\
\hline Later & ral & 283 & 4.7 & 3.9 & 851 & 3.3 & 2.6 & $Q$ \\
\hline Upp & per & 144 & 4.6 & 2.7 & 487 & 3.1 & 2.5 & \\
\hline LoW & wer & 139 & 4.7 & 4.9 & 364 & 3.4 & 2.7 & \\
\hline \multicolumn{9}{|c|}{ Canines } \\
\hline \multicolumn{2}{|l|}{ A11 } & 111 & 3.8 & 2.8 & 21 & 2.3 & 1.6 & * \\
\hline \multicolumn{2}{|l|}{ Upper } & 44 & 3.6 & 2.0 & 9 & 1.9 & .8 & \\
\hline \multicolumn{2}{|l|}{ Lower } & 67 & 3.9 & 3.2 & 12 & 2.7 & 1.9 & \\
\hline \multicolumn{2}{|l|}{ Molars } & 75 & 2.9 & 2.2 & 123 & 3.3 & 4.3 & \# \\
\hline \multirow[t]{2}{*}{ First } & Upper & 37 & 3.1 & 2.7 & 34 & 4.2 & 7.7 & \\
\hline & Lower & 30 & 2.5 & 1.6 & 86 & 2.9 & 1.8 & \\
\hline \multirow[t]{2}{*}{ second } & Upper & 4 & 3.5 & 1.9 & 2 & 3.4 & 2.9 & \\
\hline & Lower & 4 & 2.9 & 1.5 & 1 & 5.4 & & \\
\hline \multicolumn{9}{|c|}{ All Teeth } \\
\hline \multirow{2}{*}{\multicolumn{2}{|c|}{$\begin{array}{l}\text { Upper } \\
\text { Lower }\end{array}$}} & 390 & 4.3 & 2.7 & 1149 & 3.4 & 2.8 & \\
\hline & & 363 & 4.3 & 3.8 & 1182 & 3.4 & 2.4 & \\
\hline \multirow{2}{*}{\multicolumn{9}{|c|}{$\begin{array}{c}\text { * Incisors have more lead than canines in each cohort } \\
\mathrm{p}=.03 \text { in Taiwan, } \mathrm{p}=.002 \text { in Boston. }\end{array}$}} \\
\hline & & & & & & & & \\
\hline \multicolumn{9}{|c|}{$\begin{array}{l}\text { \# Incisors have more lead than molars, } \\
\qquad p=.0001 \text { in Taiwan, } p=.07 \text { in Boston. }\end{array}$} \\
\hline \multirow{2}{*}{\multicolumn{9}{|c|}{$\begin{array}{l}\text { Lateral incisors have less lead than central } \\
\text { incisors in Boston, } p=.01 \text {, in Taiwan lateral }\end{array}$}} \\
\hline & & & & & Taiwan & lat & eral & \\
\hline
\end{tabular}

molars, which are the last to form, have higher lead levels than the canines in Boston but not Taiwan.

In comparing the patterns of lead concentrations seen in this study with published accounts of similar examinations, a strikingly disparate pattern is apparent (Table 2). For example, among 7 studies compairing central to lateral incisors, the central incisors averaged higher lead levels than the lateral incisors in three and in three other groups the reverse tended to be true. The relationship between lead levels in upper and lower teeth also seems to vary among the studies.Differing analytical techniques which make use of different portions of the tooth have been used by various workers, and this can be responsible for some of the disparity. For example, Grandjean (1986) reported that upper central incisors have more or less lead than other incisors depending on whether the whole 
tooth or the circumpulal dentin is used. However, we used the same technique, measuring post-natal dentin in two cohorts, and found the central incisor to have more in Boston but not Taiwan.

These differences in lead levels among deciduous tooth types among populations are unlikely to reflect physiological factors (ie. blood supply to teeth or mineralization rates). Rather these population differences are much more lilely to depend on age related, and consequently tooth related, differences in exposure patterns among the populations. Dentin in incisors, canines, and molars calcify at overlapping but different times (Schour and Massler 1941). So they could retain varying amounts of lead. Thus, if a child's blood lead level varied widely during these years of tooth formation, different amounts of lead would be deposited in teeth at different rates (Rabinowitz et al 1984).

Calcification of a tooth never completely stops as long as there is blood supply, but the shed portions we collected, which are mostly from within the tooth crown, are deposited early in the tooth's history (Levine et al 1979). Calcification of deciduous dentin appears first within the crown, and then progressively advances towards the root and inward towards the pulp along a conical zone of mineralization. For the different tooth types these events occur at different times. For example, upper central incisors begin calcification near the third fetal month and the coronal dentin is largely completed by the third post natal month. Lower central incisors usually lag by one or two months. Canine crowns calcify during the forth through ninth post-natal months, while molars begin in utero and continue to calcify during the first year. If lead deposition were simply concurrent with calcification, and if lead exposure varied considerably during these spans of calcification, then the teeth would show different lead levels. Even if tooth lead levels represent blood lead nearer the time of shedding (Rabinowitz et al 1989), differences in exposure patterns among populations could at least partially account for these different trends.

Taiwan and Boston differ in their patterns of childhood lead expsoure. In Taipei respired lead is the major factor (Hwang and Wang, 1990), while in Boston ingested lead is the major determinant of the childs lead level (Rabinowitz et al 1985). Respiration rates (volume of air per unit of body mass) are at their maximum during infancy, but mouthing and ingestion reach their maximum during the toddler period. 
Table 2. Comparison of studies of tooth lead according to tooth type. Reported patterns of lead abundances among tooth types are shown. Some investigators analyzed the bulk tooth, other used an inner zone of dentin along the pulp cavity. We obtained the postnatal dentin from within the crown of shed teeth.

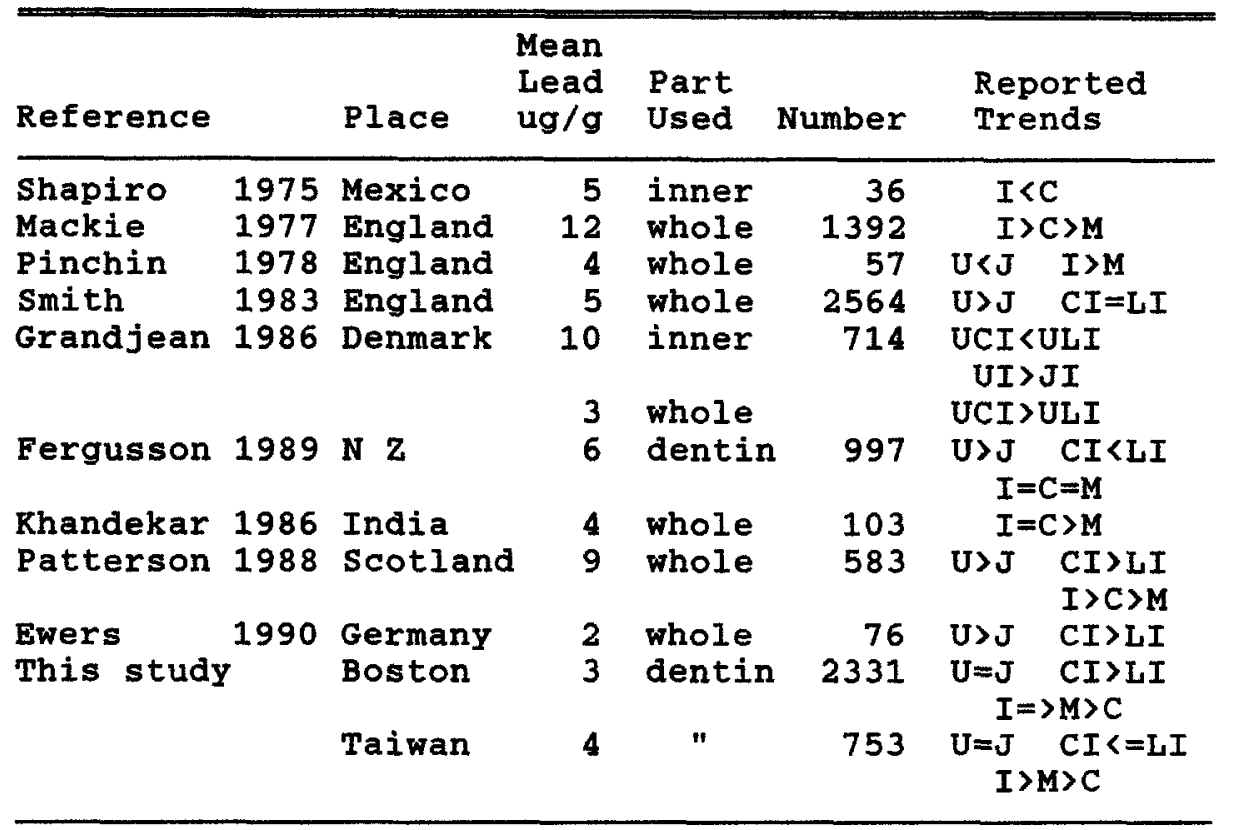

$\mathrm{U}=\operatorname{maxillary}$ tooth, J=mandibular tooth, CI=central

incisor, LI=lateral incisor

I=incisor, $C=c a n i n e, ~ M=m o l a r$

whole=entire crown analyzed,

inner=dentin near pulp cavity

Since the Chinese group included two schools near smelters and other schools in the city, we were able to examine whether the patterns of lead abundance among the tooth types were different according to this difference in lead exposure. The patterns were the same; in both sub-groups of children the incisors, canines, and molars had the same descending pattern of lead concentrations. For each tooth type the children near the smelters had higher lead levels. Thus the reported differences among investigators in the pattern among these tooth types is likely not a result of only different quantites of lead. Rather these different patterns may reflect the variety across populations of changes in exposure with age. 
Acknowledgments. The authors are grateful for the advice of Drs. Herbert Needleman and Howard Needleman and the generous cooperation of the teachers, parents and children. Excellent technical support was provided by Wen-ying Chao, Chin-siung Lu, Dr. Kun-yu Chao, Ann Lewandowski and Elizabeth Allred. Research funding was supplied by the National Instiute of Child Health and Human Development (HD 08945) and the National Science Council of the Republic of China (NSC 79-0421-B002-12).

\section{REFERENCES}

Ewers U, Turfeld M, Freier I, Ferger S, Brockhaus A (1990) Levels of lead and cadmium in deciduous teeth of children living in two different area of West- Germany. Chronolog Trend 1976- 1988 (in German) Zbl HYg 189:333-351

Fergusson $J$, Kiznet N, Fergusson D, Horwood L (1989) A longitudinal study of dentine lead levels and

intelligence, school performance, and behavior: the measurement of dentine. Sci Tot Environ 80: 229-241

Grandjean $P$, Lynbye $T$, Hansen $O$ (1986) Lead concentration of decidous teeth: variation related to tooth type and analytical technique. $J$ Tox Environ HIth 19:437-445

Hwang YH, Wang JD (1990) Temporal fluctuations of the lead level in cord blood of neonates in Taipei. Arch Environ Hlth 45:42-45

Khandekar R, Raghunath R, Mishra U (1986) Lead Levels in teeth of an urban Indian population; Sci Tot Envront 58:231-236

Levine R, Turner E, Dobbing J (1979) Deciduous teeth contain histories of developmental disturbances. Early Human Devel 3: 211-220

Mackie M, Stephens $R$, Townsend A, Waldron $H$ (1977) Tooth lead levels in Birmingham Children. Arch Environ Hlth 32:178-185

Needleman H, Tuncay C, Shapiro I (1972) Lead levels in deciduous teeth of urban and suburban American children. Nature 235:111-2

Needleman H, Rabinowitz M, Leviton A, Linn S, Schoenbaum S (1984) Relationship between prenatal lead exposure and congenital anomalies. I Am Med Assoc 251: $2956-2959$

Paterson L, Raab G, Hunter R, Laxen D,Fulton M,Fell G, Halls D, Sutcliffe $P$ (1988) Factors influencing lead concentrations in shed deciduous teeth. Sci Tot Environ 74: 219-233.

Pinchin M, Newham J, Thompson R (1978) Lead, copper, and cadmium in teeth of normal and mentally retarded children. Clin Chim Acta 85: 89-94 
Rabinowitz $M$, Leviton $A$, Needleman $H$, Bellinger $D$, Waternaux C (1985) Environmental correlates of infant blood lead levels. Environ Res 38:96-107

Rabinowitz M, Needleman H, Leviton A (1984) Variability of blood lead concentrations during normal infancy. Arch Environ Health 39: 74-77

Rabinowitz M, Beliinger D, Leviton A (1989) The blood lead-tooth lead relationship among Boston children. Bull Environ Contam Toxicol 43:485 - 492

Rabinowitz M, Wang JD, Soong WT (1991) Dentin lead and child intelligence in Taiwan", Arch Environ HIth (in press)

Schour I, Massler M (1941) The development of human dentition. J Am Dent Assoc 28:1153-60

Shapiro I, Mitchell G, Davidson I, Katz S (1975) The lead content of teeth; Arch Environ HIth, $30: 483-486,1975$

Smith $M$, Delves $T$, Lansdown $R$, Clayton B, Graham $P$ (1983) Effects of lead exposure on urban children. Develop Med and Child Neuro Supp 47, 25 : appendix d

Received February 25, 1991; accepted May 15, 1991 